\title{
Augusto Comte y sus discipulos ortodoxos frente a la cuestión colonial
}

\author{
Auguste Comte and his orthodox disciples facing the colonial \\ question
}

\author{
Tonatiun Useche Sandoval \\ Universidad de París 3 Sorbonne-Nouvelle (CRES) \\ tonatusco@yahoo.fr (FRANCIA)
}

Recibido: 21.052014

Aceptado: 08.05.2015

\section{RESUMEN}

Este artículo presenta la oposición de Augusto Comte y sus discípulos al movimiento colonizador que emanó del Occidente europeo durante el siglo XIX. Aunque considera Europa como el centro de la Humanidad, Comte sostiene que la contribución europea al progreso de los pueblos menos avanzados no reside en la dominación colonial, sino en la difusión pacífica de una doctrina demostrable. En un primer momento se resume la apreciación globalmente negativa de Comte sobre la colonización moderna; luego se evocan sus propuestas para valorar a los colonizados y combatir los argumentos colonialistas; finalmente se toma el caso de la conquista francesa de Argelia para comparar la posición de Comte con la de Tocqueville y la de Enfantin. En un segundo momento se subraya la influencia moral que sus discípulos ejercieron en Inglaterra en contra de la colonización exterior. Se insiste después en el papel significativo que jugaron sus discípulos brasileros en contra de la colonización interior y en pro de la protección de los indígenas. Se concluye que el positivismo de Comte constituye una forma de eurocentrismo anticolonial.

\section{PALABRAS CLAVE}

Colonización, política positiva, eurocentrismo anticolonial, élite de la Humanidad, pueblos atrasados, Augusto Comte. 


\begin{abstract}
This article presents the opposition of Auguste Comte and his disciples to the colonization movement which emanated from Occidental Europe in the 19th century. Even if he considers Europe as the central focus of Humanity, Comte states that European contribution to less advanced populations progress does not reside in colonial domination but in the peaceful spreading of a demonstrable doctrine. In the first part, the overall negative appreciation of Comte on modern colonization will be summarized; then his proposals to value the colonizers and to fight the colonialist statements will be mentioned; finally the case of the French conquest in Algeria will be exposed to compare Comte's position with that of Tocqueville's and of Enfantin's. In the second part, a highlight will be made on the moral influence his disciples exercised in England against external colonisation. The significant role played by his Brazilians disciples against internal colonisation and in favour of the indigenous protection will be then underlined. In conclusion, Comte's positivism constitutes a form of Eurocentric anti-colonialism.
\end{abstract}

\title{
KEY WORDS
}

Colonization, positive polity, Eurocentrism, elite of Humanity, backward populations, Auguste Comte

\section{INTRODUCCIÓN}

Para denunciar la creencia en la superioridad de la raza blanca, que justificó la desigualdad de los tiempos coloniales, Eduardo Galeano se refiere así al filósofo Auguste Comte (1798-1857): "Como casi todos sus colegas, Comte no tenía dudas sobre este principio esencial: blancos son los hombres aptos para ejercer el mando sobre los condenados a las posiciones sociales subalternas" (Galeano 2004:54). Nuestro propósito es contribuir a corregir este juicio del autor de Las venas abiertas de América latina. Comte condenó la esclavitud de los africanos durante los Tiempos Modernos como un injustificable "crimen occidental" (1929: III:520). Contrariamente a muchos de sus "colegas", el fundador de la Revista occidental reprobó sin atenuantes la avidez colonial de los europeos. A su vez, los discípulos ortodoxos de Comte jugaron un papel relevante en la denuncia de las políticas coloniales y en pro de la defensa de los pueblos colonizados.

Comte analiza y rechaza la colonización en sus dos obras maestras: el Curso de filosofía positiva donde funda la sociología, en la lecciones 53, 56 y 57, redactadas entre 1840 y 1842; y el Sistema de política positiva que instituye la religión de la Humanidad, sobre todo al final del tomo cuarto, publicado en 1854. Diversos adeptos del positivismo, como lo fue durante un tiempo John 
Stuart Mill, consideraron que la construcción religiosa rompía con el proyecto científico inicial. Sin embargo, el repudio al colonialismo constituye un factor de continuidad entre las dos carreras de Comte.

La originalidad de este filósofo reside en presentar una crítica de la colonización europea sin caer en el odio hacia lo europeo. Por el contrario, su pensamiento concilia un anticolonialismo sincero con un "profundo occidentalismo"1 (Lévy-Bruhl 2007:516). La política positiva muestra que no todo eurocentrismo engendra un colonialismo. Veamos cuál es la concepción de Occidente europeo que conduce Comte a ir a contracorriente de la fiebre colonizadora de sus contemporáneos.

Primero, sin ser un fin en sí, Europa es para Comte el centro a partir del cual se organiza la unión intelectual del género humano por encima de la diversidad de creencias. Todo organismo requiere un centro organizador; la Humanidad, siendo el organismo vivo más complejo que existe, posee un órgano que la encabeza: "la élite de la Humanidad". Esta apelación subraya una inferioridad cuantitativa que se halla compensada por una superioridad cualitativa - cuyo carácter es meramente provisorio. Sin embargo, la superioridad europea se reduce a una mayor capacidad de previsión y modificación de los fenómenos naturales y sociales, respecto a las predicciones e intervenciones que producen los pueblos menos avanzados. Este avance no otorga ningún derecho a dominar, sino el deber de difundir la religión de la Humanidad, basada en leyes impersonales y objetivas.

Segundo, el eurocentrismo de Comte deriva de razones metodológicas. Para descubrir las leyes dinámicas que rigen la evolución de las sociedades humanas, hay dos posibilidades: observar el conjunto de las historias concretas de los pueblos del mundo; o concentrar las observaciones entorno a la serie histórica más completa. Para Comte, la única opción viable es la segunda, restringiendo de manera consciente y artificial el terreno de observación a la historia de la "élite de la Humanidad", es decir concentrando el análisis en el movimiento europeo y haciendo abstracción de las trayectorias respectivas de los pueblos menos avanzados ${ }^{2}$. Pero la historia universal no se confunde totalmente con la serie europea. Comte preconiza igualmente un trabajo de abstracción interna para descartar las perturbaciones inherentes al movimiento occidental.

Comte analiza las causas y efectos ambivalentes de la colonización desde el punto de vista de la función e historia de un órgano europeo al servicio de la Humanidad. Ello lo lleva a posicionarse a favor del desmonte del sistema colonial. Para mostrarlo, dividiremos nuestra exposición en dos momentos.

${ }^{1}$ Este occidentalismo no tiene nada que ver la caricatura aborrecible de la modernidad occidental que estudia el libro de BURUMA I. y MARGALIT A., 2004, Occidentalism: The West in the Eyes of its Enemies. New York, The Penguin Press, p.6.

2 Este eurocentrismo histórico, característico del siglo XIX, es criticado hoy en día bajo el nombre de 'historicismo'. Para el historiador bengalí Dipesh Chakrabarty, el historicismo como ideología del progreso o del desarrollo hizo posible la dominación europea del mundo en el siglo XIX. Véase CHAKRABARTY D., 2000 Provincializing Europe. Postcolonial Thought and Historical Difference, Princeton, Princeton University Press, p.7. 
La sección inicial estará centrada en la obra de Comte. Después de definir los diversos tipos de colonización y precisar lo que entendemos por colonialismo, veremos cómo la conquista colonial, benéfica durante la antigüedad romana, produjo efectos ambivalentes durante la época moderna, razón por la cual Comte se opuso a la continuación de un movimiento colonizador que impedía la reorganización occidental. Estudiaremos luego las estrategias que usa Comte para lograr que los europeos valoren a los pueblos oprimidos y tomen conciencia de la inconsistencia de los sofismas con que justifican su opresión. Cerraremos esta sección tomando el ejemplo de la colonización francesa en Argelia y comparando la posición del padre de la sociología con la de dos pensadores de su época: Alexis de Tocqueville, diputado durante reinado de Luis Felipe, y Prosper Enfantin, líder de los sansimonianos, con quienes Comte tiene varios puntos en común.

La segunda sección girará en torno a consideraciones históricas que subrayarán la posteridad de la posición comtiana y el papel de los positivistas en la lucha contra el colonialismo. Nos interesaremos sobre todo en el caso de Richard Congreve, un discípulo británico cuya protesta contra la colonización inglesa suscitó la adhesión al positivismo de una porción de las élites hindúes. Finalmente, detallaremos más ampliamente el rol considerable que desempeñaron los positivistas brasileros en la protección de las comunidades indígenas brasileras contra la colonización interior y sus justificaciones raciales.

\section{AUGUSTO COMTE, UN EUROCÉNTRICO ANTICOLONIAL}

\subsection{Definición, apreciación histórica y crítica eurocéntrica de la colonización}

Conviene definir el verbo colonizar. Cabe destacar tres acepciones. Primero, en un sentido extenso, significa que un pueblo extranjero recurre al uso de la fuerza para someter, por intereses militares, económicos o demográficos, un territorio poblado y organizado. Tal fue la colonización que ejerció en India el imperio inglés. Este es el sentido más frecuente del término en la obra de Comte: el poder absoluto que ejerce un país sobre una población extranjera. La segunda acepción designa la fundación y población de una ciudad en un territorio inhabitado o poco poblado. Una vez asentada, la ciudad se independiza de la metrópolis. Tal fue el tipo de colonización que practicaron los ciudadanos griegos en Asia menor, entre los siglos VII y V antes de nuestra era, al igual que los colonos ingleses y franceses en Norteamérica en los siglos XVI y XVII. La tercera acepción significa poblar por la fuerza un territorio ya habitado pero con escasas infraestructuras, no sólo para explotarlo sino también para modernizarlo. Tal fue la colonización francesa en Argelia en el siglo XIX En cuanto al colonialismo, se trata de una justificación del acto de colonizar, sobre todo en su primera y tercera acepción, arguyendo la supuesta y definitiva superioridad del pueblo dominante sobre las poblaciones dominadas. La reprobación de 
Comte está dirigida contra el colonialismo y contra la colonización practicada en zonas lo bastante pobladas como para que la intervención europea perturbe el desarrollo de las sociedades autóctonas ${ }^{3}$.

Los efectos de una institución difieren según el estado de civilización de una sociedad. Para Comte, un organismo social se civiliza remplazando progresivamente las concepciones teológicas y las actividades militares, inseparables de la infancia de la Humanidad, por un régimen adulto, basado en el conocimiento de las leyes naturales y en la modificación de la naturaleza mediante la aplicación de las ciencias. Para comprender la colonización, como sometimiento y ocupación parcial de uno o varios pueblos por una potencia extranjera, hay que situarla dentro de las etapas de la historia de la civilización en Occidente.

La idea de imperio colonial evoca nociones romanas. Para Comte, las conquistas de Roma representaron un progreso con respecto a las guerras interminables y destructoras entre las ciudades griegas. Roma incorporó por la fuerza a sus vecinos dentro de un sistema de pueblos politeístas y militares que puso en marcha la unidad occidental (1929: III:354, 379), porque para los romanos la guerra se terminaba cuando se concluía una alianza (Arendt 1990:202). El epílogo del combate ya no era el exterminio de los guerreros derrotados, sino su integración dentro del ejército o del aparato productivo del pueblo romano. La pax romana surgió del monopolio de la actividad militar (1929: III:349), pero también del desarrollo de obras públicas (vías, acueductos) y de la difusión de las mejores realizaciones de los pueblos vencidos, como el saber griego (1929: III:357, 384). Los romanos aceptaban su "secundaridad cultural" (Brague 1998:157) y estaban dispuestos a conservar e imitar los usos extranjeros que les parecieran más civilizados que los suyos. Sin embargo, Comte estima que el sometimiento de Oriente por las legiones romanas resultó perturbador y codicioso, ya que en aquellas regiones, la "incorporación forzada" era imposible por tratarse de otro tipo de sociedades, nómadas o teocráticas (1929: III:384).

Durante el medioevo, las cruzadas no fueron una tentativa fracasada de colonización sino una estrategia para defender a Occidente de las invasiones musulmanas (1975: II:354; 2012:654). Durante los Tiempos Modernos, la colonización renace como fruto de la desorganización y reorganización europeas. Cuando se fractura en el siglo XIV la unidad religiosa, la "república occidental" se descompone en diversas unidades políticas, centradas en torno a la monarquía en los países católicos como Francia o España, y en torno a la aristocracia en los países protestantes como Inglaterra (1975: II:414; 2012:743). La falta de creencias comunes convierte a la guerra exterior en el cimiento de la paz y la prosperidad de cada Estado. "La expansión exterior surgió durante la anarquía interior" (1929: IV:502). El statu quo entre las potencias occidentales,

${ }^{3}$ Establecemos esta tipología apoyándonos en los análisis del sociólogo Raymond Aron, gran conocedor de Comte y de las relaciones internacionales: ARON R., 1962, Paix et guerre entre les nations. París, Calmann Lévy, pp.263-271 y 2006, Les sociétés modernes. París, PUF, pp.991-993. 
su proteccionismo económico, junto con los progresos de la navegación y la intrepidez de los exploradores europeos, condujeron a la conquista de pueblos y recursos en ultramar. La colonización provino de naciones políticamente concentradas, lo cual excluyó a Italia del proceso (1975: II:516; 2012:896). Comte distingue dos clases de colonización. Su tipología no reposa en la finalidad de la conquista, poblar o explotar, sino en el tipo de metrópoli, católica o protestante. Ambos tipos fueron opresivos, pero el primero era más sistemático y regulado, mientras que el segundo era más espontáneo y anárquico. Los colonizadores católicos representaban una autoridad política que los protestantes cuestionaban o esquivaban (1929: IV:495). Según Comte, la colonización protestante fue más voraz que la colonización católica, como lo ilustra la avidez de los holandeses en Indonesia (1975: II: 520; 2012:902).

Desde esta perspectiva eurocéntrica, las colonizaciones fueron un "gran acontecimiento europeo" (1975, II:520; 2012:902) que aceleró el progreso de la élite de la Humanidad: extendieron el horizonte de la sociabilidad y replantearon la cuestión de la universalidad de la civilización occidental; favorecieron el desarrollo industrial en todo el Occidente europeo, incluso y sobre todo en los países desprovistos de colonias. La opinión de Comte prolonga el pensamiento del escocés Adam Smith: "Las principales ventajas que obtuvo Europa, considerada como un solo gran país, con el descubrimiento y colonización de América, fueron, primero, el aumento de sus posesiones y, segundo, el incremento de su industria" (1863:265). Cabe precisar que la industria significa el conjunto de las actividades pacíficas agrícolas, manufactureras y comerciales. Así, Comte conmemora a los grandes navegantes y descubridores, Marco Polo, Colón y Cook, como héroes de la industria moderna (Comte 1993:31).

Por otra parte, la colonización provocó el estancamiento de los países colonizadores. Esta retrogradación constituye un "justo castigo" (1975: II:522; 2012: 905) por la opresión ejercida en ultramar. En el caso de España, el dominio colonial provocó la conservación del régimen católico y guerrero, causa de su posterior letargo intelectual y económico. Respecto a Inglaterra, la retrogradación, aunque menos evidente, reside en una actividad militar rejuvenecida a causa de las guerras comerciales y en una reconversión industrial de la casta aristocrática. Las conquistas por fuera sirvieron para compensar la compresión social que padecía por dentro el pueblo inglés (Comte, 1990:255258).

Considerando la dinámica histórica de Europa, Comte anuncia el fin de la era colonial y denuncia la fiebre colonizadora que afecta a los europeos como un obstáculo a su regeneración. Mantener y extender la colonización en el siglo XIX, no sólo era desconocer los cambios acontecidos en Europa tras la revolución francesa, era ignorar también que la Humanidad es el único organismo vivo compuesto de órganos independientes. Por un lado, la fiebre colonizadora pasaba por alto uno de los escasos aportes de la política metafísica que, extrapolando la libertad de conciencia a las relaciones internacionales, afirmó la independencia de los pueblos contra las ambiciones imperiales. La lucha de las naciones contra los imperios empezó cuando la revolución 
holandesa sacudió el yugo español, alrededor de 1570 (1975: II:432; 2012:771). Comte interpretó como un indicador de la decadencia del sistema colonial la emancipación de la América inglesa en 1783, de la América española hacia 1820 (1929: III:612), sin olvidar la de Haití frente a Francia en 1804. Por otro lado, colonizar significaba malgastar las fuerzas europeas en una empresa condenada al fracaso, cuando lo urgente era la reorganización pacífica y científica de las sociedades occidentales. En vez de promover la occidentalidad, las colonizaciones alimentaban los antagonismos entre los Estados. Luego, había que invertir la lógica colonial: en vez de diferir la resolución de la "anarquía occidental" subyugando a los pueblos menos avanzados, importaba más aplazar las intervenciones por fuera y vincular a los pueblos más adelantados, gracias a una doctrina demostrable y a la cooperación industrial (1975: II:237; 2012:478).

\subsection{Las propuestas del positivismo a favor de los colonizados y en contra de los argumentos colonialistas}

Esta evaluación finalmente negativa de la colonización moderna conduce Comte a combatir la avalancha europea que arremetía contra los pueblos menos avanzados. Su estrategia se basa en hacer apreciar a los oprimidos y en disipar los sofismas de los opresores (1929: IV, 520).

Comte promueve incluir dentro de un calendario destinado al público occidental, a los personajes históricos representantes de la excelencia de pueblos que aunque estaban menos desarrollados no eran para nada retrasados. Se trata de un sistema de conmemoración que consagra cada día, semana y mes del año a un gran tipo, masculino o femenino, de la Humanidad. Varios héroes provenientes de los pueblos colonizados se hallan en el mes inicial, reservado a la teocracia. Entre los glorificados están Buda, Confucio o Mahoma, al igual que el fundador del imperio inca, Manco Capac, o el rey que unificó las islas Hawaï, Kamehahea (1993:23 y 1975: II:803). Hacen parte también del "panteón positivista" $(1993: 18,34)$ Bolívar y Toussaint-Louverture a quien Pierre Laffitte, discípulo y sucesor de Comte en Francia, compuso un homenaje (Laffitte: 1882). Sin embargo, Comte sabe que un calendario concreto, consagrado a los personajes históricos es imperfecto, porque no abarca a los pueblos sin memoria escrita que no transmitieron el nombre de sus grandes hombres a la posteridad. Por ello, se esmera en "honrar" el modo de pensar de las poblaciones sin escritura, es decir de las poblaciones fetichistas (Comte 2009:285).

Por razones no solamente políticas sino también teóricas, Comte incorpora progresivamente dentro del positivismo el estado intelectual espontáneamente vigente en los pueblos menos avanzados, el fetichismo ${ }^{4}$. Se trata de una explicación del mundo a partir del hombre, basada en la personificación de todos

4 A este respecto, GANE M., 2007, « Fétichisme et politique positive ». Archives de philosophie, 1, pp.23-40 y BOURDEAU M., 2006, Les Trois États : Science, théologie et métaphysique chez Auguste Comte. París, Cerf, pp.82-88.

EMPIRIA. Revista de Metodología de Ciencias Sociales. N. ${ }^{\circ}$ 31, mayo-agosto, 2015, pp. 79-96. ISSN: 1139-5737, DOI/empiria.31.2015.14538 
los objetos. Resulta irónico, anota Comte, que occidentales que desprecian la inocencia de los pueblos fetichistas, los imiten cuando maldicen una máquina descompuesta que no quiere funcionar (1975: II:247; 2012:492). Un aporte intelectual del fetichismo consiste en la adoración de la materia (1929: III:122). Ese respeto del fetichista por su fetiche, que toma la forma de un fatalismo, prefigura la subordinación del espíritu positivo a las leyes naturales. Aunque imperfecto, el fetichismo es irreprochable y constructivo (Canguilhem, 1968:93). Poco admirador del idealismo alemán, Comte prefiere la inocente ignorancia de los pensadores de África central, a las habladurías de los doctores germánicos (1929: III:99).

Comte busca que los europeos reconozcan la dignidad de los pueblos colonizados y la indignidad de sus colonizadores. Por lo demás, considera que los pueblos más atrasados de Europa occidental en 1850, no eran Italia y España, sino Inglaterra y las naciones germánicas, por mostrarse despóticas en su política extranjera. Comte le reprocha a la primera su creciente imperio colonial y a las segundas, en particular a Austria, su acción represiva en contra de la península itálica (1929: IV:490 y Couderc-Morandeau: 2007:65). Sin embargo, Comte no se contenta con indignarse sino que combate las justificaciones según las cuales es digno que los países europeos colonicen a los menos desarrollados con el fin de remplazar los usos de los pueblos bárbaros por los de la sociedad occidental, suplantando los despotismos locales, anárquicos, por un despotismo europeo, progresista.

Comte denuncia la tesis que afirma la necesidad de la colonización a causa de la incompatibilidad entre la civilización de las naciones avanzadas y la barbarie de los pueblos apegados a un tenebroso pasado. Este planteamiento consiste en creer que un pueblo menos avanzando no puede civilizarse por sí mismo, sino que tiene que ser civilizado mediante la intervención colonial. A pesar de su cosmopolitismo, la doctrina del siglo de las luces mantiene la dicotomía entre civilización y barbarie, ya que ignora el valor de la tradición y desconoce los logros de los pueblos tradicionales. Comte admira el Esbozo de un cuadro histórico de los progresos del espíritu humano de Condorcet, pero le reprocha su desprecio por el medioevo, que le impide comprender el progreso como filiación histórica (1975: II:90; 2012:259). Este desprecio conduce en Condorcet a considerar que los pueblos menos desarrollados están sumidos en el error y la ignorancia. En cambio, Comte rechaza la idea que una parte de la humanidad esté condenada a la barbarie. Comte denuncia a quienes pretenden civilizar ya sea a los supuestos bárbaros de afuera, las tribus salvajes del extranjero, ya sea a las supuestas hordas bárbaras de adentro, los salvajes proletarios del interior. En la óptica de la política positiva, cada pueblo, cada época, cada clase se encuentran de entrada y de lleno en el marco de la civilización, la única diferencia reside en la velocidad de este proceso (1975: II: 147; 2012:342).

Por consiguiente, Comte rechaza la tesis que sostiene que, como Occidente es la élite de la Humanidad, bastaría con exportar las instituciones de los países desarrollados para mejorar el estado de los pueblos menos avanzados. Desde 
esta perspectiva, "civilizar" se reduce a practicar un "trasplante facticio" de tipos inmutables, a pesar de la evidente diferencia de condiciones (1975: II, 522n; 2012:905n). Para Comte, este "proselitismo" fomenta una "ciega imitación rutinaria" (1975: II:691; 2012:1161) de Occidente y perturba el desarrollo espontáneo de los demás pueblos. Podríamos decir que, para Comte, la occidentalomanía del siglo XIX era tan aberrante e inefectiva como la “anglomanía” legada por el siglo de las Luces (1975: II:414; 2012:743).

Para adentrarnos en un segundo tipo de justificación, nos referiremos a John Stuart Mill, gran adepto de Comte durante algunos años, quién publicó en 1862 unas Consideraciones sobre el gobierno representativo. En el último capítulo del libro, consagrado a la cuestión colonial ${ }^{5}$, Mill distingue entre las colonias pobladas por europeos y las habitadas por pueblos atrasados. En las primeras, se requiere un gobierno representativo que les permita depender de sí mismas. Las segundas, en cambio, aún no están preparadas para ser independientes. Ya en su libro Sobre la libertad, Mill escribía: "El despotismo es una forma legítima de gobierno cuando se trata con bárbaros, siempre y cuando la meta sea su mejoramiento y los medios se justifiquen alcanzando la meta" (1859:23). El inconveniente es que "bajo un despotismo indígena, un déspota bueno es un accidente transitorio y poco frecuente" (1865:134). De allí la utilidad de la colonización europea: instaurar un despotismo estable e ilustrado que enmiende la precariedad de los "despotismos bárbaros". Mill afirma que "la condición ordinaria, con tendencia a volverse prontamente universal, de los pueblos atrasados es encontrarse bajo la sujeción directa de los pueblos avanzados, o bajo su completa influencia política" (1865:134).

Al seguidor de los años 1840, la obra de Comte opone al menos dos argumentos. Primero, que el despotismo generado por la Compañía inglesa de Indias, cuya organización sirve a Mill de referencia (1865:140), asocia de manera peligrosa el poderío militar y la capacidad industrial. Confundir a los militares con los industriales implica no sólo retardar la regeneración pacífica de Europa sino también correr el riesgo de una retrogradación. En efecto, con el despotismo industrial, la sociabilidad moderna, basada en el dominio de la naturaleza gracias al trabajo humano, se pone entonces a imitar la sociabilidad antigua que reposa en la sumisión de un pueblo a otro. Por ello, la "esclavitud indígena", ejercida por tribus fetichistas y guerreras, contiene, para Comte, un mayor potencial civilizador que la colonización despótica de las naciones avanzadas (1975: II:522n; 2012:905n). Segundo, no son los pueblos atrasados los que aún no están listos para acoger los beneficios teóricos y prácticos elaborados en Occidente. Son las naciones occidentales las que aún no están preparadas para trasmitir, sin segunda intención, sus adelantos, puesto que aún no han sido capaces de superar el estado de revolución permanente que las desgarra y que las ha convertido en un factor perturbador para el resto de la Humanidad (1975: II:692; 2012:1162). libre".

${ }^{5}$ Se trata del capítulo XVIII titulado "Sobre el gobierno de las dependencias de un Estado 
Tras mostrar la perspectiva eurocéntrica de Comte, destacamos su análisis ponderado de las causas y consecuencias de la colonización emprendida por los europeos, para poner después en relieve la oposición del filósofo a la permanencia o extensión del movimiento colonizador. Con miras a subrayar la originalidad de este planteamiento, terminaremos esta primera sección abordando el caso concreto de la colonización francesa en Argelia.

\subsection{El caso de la colonización de Argelia: la posición de Comte comparada a la de Tocqueville y a la de Enfantin}

Cuando, en 1852, Comte toma públicamente posición contra la colonización de Argelia, el ejército de Francia, tras dieciocho años de una lucha que movilizó más de cien mil militares, ya había terminado la difícil conquista de un territorio que se convirtió en 1848 en departamento francés. La controversia acerca de Argelia surgió en los años 1840 como una respuesta de los intelectuales franceses a los excesos provocados por una colonización militar, centrada en la represión de los rebeldes argelinos mediante el establecimiento de colonias centinelas y organizada por el Mariscal Thomas-Robert Bugeaud ${ }^{6}$ (1784-1849) quien declaraba: "Los sometieron por las armas, sólo los mantendrán sometidos por las armas" (Couderc-Morandeau 2007:43 y 85). Antes de abordar la opinión de Comte sobre este tema, consideremos la posición de dos intelectuales de renombre, contemporáneos del filósofo: Alexis de Tocqueville y Prosper Enfantin.

Alexis de Tocqueville (1805-1859) estuvo unos meses en Argelia en 1846 como diputado miembro de una comisión parlamentaria que evaluó la política colonial de Bugeaud. Si su informe negativo provocó la renuncia del mariscal, fue para apoyar el proyecto colonizador del general Louis de Lamoricière, quien conoció a Comte como profesor particular de matemáticas. Tocqueville estaba a favor de una colonización civil, respaldada por compañías financieras. En carta dirigida a Lamoricière del 5 abril de 1846, le declara anhelar el "establecimiento de una sociedad europea y cristiana en el suelo de Argelia". Le aconseja también considerar las revoluciones sociales y políticas que podrían dislocar la sociedad argelina y "desgastar la fuerza moral del pueblo vencido". (Tocqueville 2003:562)

El "padre" de la iglesia sansimoniana, Prosper Enfantin (1796-1864), viajó a Argelia en 1839 y publicó en 1843 el libro Colonización de Argelia. Aunque aceptaba la necesidad de colonias militares para combatir a los rebeldes,

${ }^{6}$ Cabe recordar que Bugeaud no estaba de acuerdo con la colonización. Así, en un discurso del 15 de enero de 1840 declara: "El abandono [de Argelia]: la Francia oficial [...] no lo quiere, es decir los escritores, la aristocracia del escritorio no lo quiere. [...] Sí, a mi parecer, la posesión de Argel es una falta, pero como quieren hacerlo, como es imposible que no lo hagan, tienen que hacerlo con grandeza [...]. Luego es preciso que ese país sea conquistado y el poder de Abd-el-Kader destruido", Ver AZAN P., 1948, Par l'épée et par la charrue, Ecrits et discours de Bugeaud. París, PUF, pp.61-71

EMPIRIA. Revista de Metodología de Ciencias Sociales. N. o 31, mayo-agosto, 2015, pp. 79-96 ISSN: 1139-5737, DOI/empiria.31.2015.14538 
promovía restringir el uso de la fuerza y evitar las expediciones militares para que Francia salvaguardara en África el monopolio intelectual y moral (CoudercMorandeau 2007:93). Dado que admiraba el espíritu comunitario de los árabes que contrastaba con el individualismo europeo, se oponía a la importación de instituciones jurídicas francesas como la propiedad privada (Collinet 1961:43, 44). Para los sansimonianos, Argelia no era un territorio, sino un laboratorio donde se jugaba la reforma de la sociedad occidental y la solución de sus contradicciones internas gracias a la mezcla de los progresos científicos europeos con el espíritu colectivo árabe y la transformación del ejército en un órgano consagrado a la construcción de obras públicas (Collinet 1961:45). Aunque esta idea no fuera de San Simón, Enfantin esperaba convertir a los indígenas en "soldados de la industria" y a los jefes militares en ingenieros civiles (CoudercMorandeau 2007:85). Ex-alumnos como Comte de la Escuela Politécnica, los sansimonianos consideraban la industria como una herramienta esencial de su política colonial, en consecuencia, tomaron parte en importantes proyectos de obras públicas que no lograron siempre concretar, por ejemplo la construcción del Canal de Suez. El prestigio de los éxitos industriales debía favorecer la adhesión de los indígenas a la civilización occidental.

En 1852, Comte se posiciona como un adversario de la colonización francesa en Argelia. Su propuesta es sencilla: Francia debe restituirle Argelia a los árabes (1929: IV:471), del mismo modo, les recomienda a los ingleses desmontar su imperio colonial restituyéndole Gibraltar a España (1929: IV:493). Cierto que Francia es el centro de Occidente, y que Occidente es el centro de la Humanidad, pero el papel de ambos ha de ser espiritual o moral, no temporal o material. Comte había anhelado de joven la victoria de los españoles sobre las tropas de Napoleón (2009:322). Ya viejo, deseó que los rebeldes argelinos, siguiendo el ejemplo del emir Abd-el-Kader, vencieran a los franceses en caso de que sus coterráneos no aceptaran su propuesta de restitución. Sin embargo, como ya lo pudimos constatar, la mayoría de sus contemporáneos estaban a favor de la colonización en Argelia, aunque bajo modalidades diferentes 7 . Incluso algunos de los discípulos franceses del filósofo no compartían su simpatía por el pueblo argelino. Así, el importante lexicógrafo y fiel republicano, Emile Littré (18011881), quien difundió el positivismo aunque no se reconociera en la religión de la Humanidad, le escribió a Comte: "No les tengo, lo confieso, ninguna simpatía a los árabes ni a Abd el-Kader, y preferiría ver allí a los franceses que a aquellos" (Pickering 2009: II:476).

Esta breve comparación devela que la posición de Comte sobre el caso de Argelia, aunque formulada de manera algo tardía, fue más radical que la de

7 Según la historiadora Mary Pickering, Ismayl Urbain (1812-1884) fue uno de los pocos franceses que protestó contra la colonización y el proceso de asimilación, hasta volverse uno de los portavoces de Argelia para los argelinos (Pickering 2009: III:272). Este mestizo francés, simpatizante del sansimonismo, se fue a Argelia en 1837. Se convirtió al Islam, estudió la sociedad árabe y sirvió como intérprete entre franceses y musulmanes. Cabe agregar que Urbain publicó en 1861, bajo un seudónimo, el libro Argelia para los argelinos, que a pesar de lo que sugiere el título no contiene una reivindicación de independencia (Urbain 1861:16 y 157) 
muchos de sus ilustres contemporáneos. Los tres son eurocéntricos, salvo que para Tocqueville o Enfantin, el proceso de civilización de un pueblo atrasado requería su colonización por un país a la vez civilizado y civilizador. Sin embargo, un eurocentrismo anticolonial corre el riesgo de ser considerado como utópico. Por ende, examinaremos, en una segunda sección, cómo se manifiesta este anticolonialismo en la posteridad positivista.

\section{LOS DISCÍPULOS ORTODOXOS DE COMTE CONTRA LAS COLONIZACIONES EXTERIOR E INTERIOR}

Los discípulos ortodoxos de Comte, los que adhirieron plenamente a la Religión de la Humanidad fundada en el Sistema de política positiva, mantuvieron viva la lucha de su maestro a favor de los pueblos oprimidos. Comenzaremos estudiando su papel frente a la colonización exterior que convirtió, durante la segunda mitad del siglo XIX, a Francia y a Inglaterra en dos inmensos imperios coloniales. Y terminaremos viendo cómo los discípulos brasileros adaptaron el pensamiento de Comte para criticar una forma de opresión que Comte no había considerado: la colonización interior de territorios indígenas por colonos blancos en un país independizado.

\subsection{La crítica vigorosa de los discípulos ingleses en contra de la colonización exterior}

Si el segundo imperio de Napoleón III estuvo influenciado por el sansimonismo, la Tercera República francesa lo estuvo por el positivismo. Sin embargo, Pierre Laffitte, líder del movimiento positivista tras el deceso de su fundador, adoptó frente a la colonización francesa una posición al final de cuentas menos intransigente que la de Comte. Laffitte no criticó a Jules Ferry, personaje emblemático del republicanismo francés, cuando éste declaró: "La política colonial es el derecho de la razas superiores frente a las inferiores y es el ejercicio de un deber" (Couderc-Morandeau 2007:79). La falta de entusiasmo de Laffitte para denunciar el imperio colonial de Francia le valió duros reproches por parte de los positivistas ingleses quienes optaron por proseguir el combate de Comte contra la colonización.

Richard Congreve (1818-1899), quien fuera destacado docente de la universidad de Oxford, es una de las figuras más representativas del positivismo en Inglaterra. Conoció a Comte en 1848. En 1855, decide dedicarse a propagar la religión de la Humanidad en Inglaterra. Como Comte no quería que la solicitud de restituir las colonias apareciera un acto de injerencia, sino que fuera un acto espontáneo, le recomendó a su discípulo que tomara la iniciativa de formular

8 "Una historia ideológica seria de la República en Francia supone obligatoriamente referirse al positivismo" (Nicolet 1994:238). Lo mismo puede afirmarse de la República en Brasil.

EMPIRIA. Revista de Metodología de Ciencias Sociales. N. ${ }^{\circ}$ 31, mayo-agosto, 2015, pp. 79-96. ISSN: 1139-5737, DOI/empiria.31.2015.14538 
esta petición. Congreve publicó dos panfletos contra las posesiones inglesas en Europa y Asia: Gibraltar (1855) e India (1857). El panfleto India merece un breve comentario, ya que fue escrito como un homenaje fúnebre de Congreve a Comte, quien falleció el mismo año que la rebelión y represión de los cipayos. Congreve retoma fielmente la tesis de su maestro. Pide que se trate por igual a los inculpados indígenas e ingleses: "Si no hay ninguna clemencia para el cipayo, ique tampoco haya ninguna para el europeo culpable!" (Congreve 1858:16). Sostiene que si se quiere subordinar la política a la moral, se debe acabar con la ocupación inglesa, asegurar la independencia de India e instituir saludables relaciones comerciales y morales entre oriente y occidente (Congreve 1858:53, 83). La prensa británica criticó severamente una propuesta tildada de "antipatriótica y anticristiana". Congreve se volvió entonces tan impopular que perdió todos sus alumnos (Wright 1986:73-88).

El texto de Congreve atrajo la atención de una parte de las élites hindúes hacia el positivismo. Alrededor de 1870, nació la Sociedad positivista de Bengala, impulsada por Congreve (Bagchi 2003:247). De hecho, Comte consideraba la casta de los brahmas en India como una especie de poder espiritual que podría estar interesado por su filosofía ya que "sólo el positivismo puede procurarles a los brahmas regenerados la satisfacción de los nobles deseos que siempre cobijaron de liberar la patria teocrática de toda dominación exterior" (1929:IV:514). Ghosh Jogendra Chandra (1842-1902), uno de los líderes positivistas en Bengala se inspiró de Comte para subrayar el valor de las instituciones tradicionales hindúes y para modernizar el orden jerárquico brahamánico (Bagchi 2003:251). Se cumplía así un anhelo de Comte: valorar los usos de los pueblos oprimidos para suscitar su modificación desde el interior.

\subsection{Los positivistas brasileros en contra de la colonización interior y a favor de la protección de los indígenas}

El caso de Brasil nos permitirá abordar la cuestión de la oposición de los positivistas contra la colonización interior. La independencia de 1822 emancipó las élites brasileras de la corona de Portugal, pero no hizo desaparecer el sometimiento de los indígenas. La colonización prosiguió pero ya no organizada por un actor extranjero, sino por uno nacional. La colonización interior, emprendida por la élite blanca y católica, descendiente de europeos, mantuvo los objetivos de la colonización portuguesa: catequizar y civilizar a los indígenas agrupándolos entorno a aldeas (Buchillet 1997:74); entregar las tierras "desinfectadas" de indios a colonos blancos que las hicieran productivas (Buchillet 1997:78); combatir y esclavizar a aquellos que opusieran resistencia. Bajo el imperio, los indios que los colonizadores portugueses habían calificado de "salvajes" fueron considerados como un obstáculo para el desarrollo económico, ya que se resistían a la invasión de sus territorios por los frentes de expansión agrícola (idem). Los colonos brasileros los denigraron acusándoles de ser antropófagos, sanguinarios y "salvajes". 
La pertenencia de los indios al género humano fue puesta en duda cuando se cuestionó su capacidad para progresar, lo que implicaba que era inútil educarles y que la única manera de tratar con ellos era exterminándolos, como lo proponían los colonos. Uno de los defensores de esta tesis, fue el gran historiador de la época imperial, Francisco Adolpho Varnhagen (1816-1878). Varnhagen estimaba que frente a los indios "salvajes" o insumisos, no quedaba más remedio que declararles la guerra y retirarles las tierras fértiles que le robaban a la civilización. Así, el indio se convertía en el intruso, usurpador del territorio brasilero, mientras que el colonizador blanco, extranjero que había adquirido la nacionalidad brasilera, aparecía como el verdadero actor de la historia nacional.

Según Varnhagen, la incapacidad de los indios para progresar provenía de una deficiencia innata, debida a la raza (Buchillet 1997:79-80). En efecto, la colonización interior estuvo marcada por una corriente seudo-científica que sostenía la desigualdad racial. Dom Pedro II veía en la inmigración europea y el 'blanqueamiento' de la población una respuesta contra la decadencia nacional. No en vano el emperador admiraba a Arthur Gobineau quien trabajó en la embajada de Francia en Brasil entre 1869 y 1871 (García Parpet 2003:224-225). Bajo la República, las violencias provocadas por la colonización interior se recrudecieron y el argumento racial siguió autorizando una lucha sin escrúpulos contra los indígenas. Así, Hermann von Ihering, zoólogo alemán establecido en Brasil, utilizó su prestigio científico para difundir la idea que los indios "salvajes" que rechazaban a los colonos y jesuitas, estaban condenados a desaparecer, por pertenecer a una raza en vías de degeneración (Kury 2003:134).

Hacia 1850, el positivismo empieza difundirse en Brasil, sobre todo gracias a la escuela militar de Río (Arbousse-Bastide: 1979)9 . Tras la proclamación de la República en $1889^{10}$, los positivistas brasileros jugaron un papel significativo en la defensa de los grupos indígenas. En primer lugar, los discípulos de Comte en Brasil asumieron una posición crítica frente a las justificaciones de la colonización interior basadas en la desigualdad entre las razas. Por una parte, los discípulos ortodoxos de Comte afirmaron la capacidad de todos los seres humanos, y por ende de todos los grupos autóctonos, a progresar y a ser educados. Por otra, sostuvieron que los diferentes niveles de civilización no derivaban principalmente de diferencias orgánicas o raciales, sino de un tipo distinto de organización social. En efecto, Comte rechaza la "irracional noción de las razas" (1929:II:449) que niega el papel de la evolución histórica y reduce la sociología a un "materialismo fisiológico", retomando una expresión de Pierre Laffitte ${ }^{11}$. Comte reconoce, sin embargo, una influencia de la raza

9 Sobre el establecimiento y propagación del positivismo en Brasil, consultar los trabajos de Paul Arbousse-Bastide. .

10 "Los discípulos de Comte fueron un actor importante en la elaboración de los símbolos republicanos. El lema, ordem e progresso, y el color verde del estandarte brasilero que diseñó el pintor positivista Décio Villares, fueron inspirados por la bandera que Comte había imaginado para la República occidental.

${ }_{11}$ Ver Petit, 2013.

EMPIRIA. Revista de Metodología de Ciencias Sociales. N. ${ }^{\circ}$ 31, mayo-agosto, 2015, pp. 79-96 ISSN: 1139-5737, DOI/empiria.31.2015.14538 
sobre la velocidad del proceso civilizador, pero su importancia es secundaria y además se atenúa con el mestizaje y el progreso social (1929:II:462). Existen tres razas principales, la blanca, la negra y la amarilla, que personifican los tres aspectos esenciales de la naturaleza humana, la especulación, la afección y la acción. Comte no establece ninguna jerarquía entre ellas, lo cual impide todo mutuo desprecio. "Los negros se hallan tan por encima de los blancos en cuanto al sentimiento como por debajo de ellos en cuanto a la inteligencia [...] La raza amarilla me parece tan superior a las dos otras en cuanto a la actividad como éstas lo son respectivamente en lo que concierne la inteligencia y el sentimiento" (1929: II:462). Pero si hubiera que jerarquizar, la raza favorecida no sería la blanca, sino la negra (Kury 2003:129 y García Parpet 2003:236) ya que la religión de la Humanidad no es intelectualista: el espíritu es el ministro del corazón, y el amor, el principio de toda actividad y pensamiento (Comte 1998:60).

En segundo lugar, los positivistas brasileros pusieron en evidencia los derechos de los pueblos indígenas y los deberes de los colonos blancos. Por una parte, resaltaron que los aborígenes no cometían ningún acto de barbarie al defender sus territorios ancestrales de la expansión agropecuaria. De hecho, consideraban que Brasil estaba compuesto de Estados occidentales brasileros, "sistemáticamente confederados", mezcla de europeos, africanos e indígenas, y de Estados americanos brasileros, formados por las "hordas fetichistas empíricamente confederadas" y dispersas por todo el territorio de la República. Esta consideración introdujo el principio que la confederación empírica de hordas fetichistas tenía el derecho a proteger cuando sus tierras eran invadidas (Buchillet 1997:82-84). Por otra parte, los positivistas promovieron la idea que el poderío que brinda el desarrollo teórico y práctico no le da a la élite blanca un derecho de colonización sobre las comunidades menos desarrolladas, sino que le impone un deber de protección. De esta manera, asimilaron los desmanes cometidos por los colonizadores contra los indios como un atropello cometido por un fuerte contra un débil.

El ejemplo que resume la oposición de los positivistas brasileros a la colonización interior es el caso de Cándido Mariano Rondon (1865-1958), quien mostró ante los ojos de la opinión que todos los grupos indígenas podían ser integrados dentro de la sociedad brasilera. Rondon siguió una exitosa carrera militar, orientada hacia la enseñanza de las ciencias y los trabajos de ingeniería civil. En sus relaciones con los aborígenes imperaba este principio: "Morir si hace falta pero matar jamás". Este lema pacífico concuerda con el altruismo fomentado por Comte y contrasta con la postura de Ihering, quién criticaba el "filoindianismo epidémico" de los positivistas (Menezes Ferreira 2005:428). Lo cierto es que el general Rondon obtuvo logros. Sosegó regiones con conflictos violentos sin usar las armas. Controló el acceso a los territorios de los aborígenes, creando en 1910 un servicio estatal de protección indígena. Les enseñó a los indios la agricultura y la ganadería sin proceder a ningún proselitismo religioso. Convenció ciertas comunidades para que trabajaran en la instalación de postes telegráficos en el Mato Grosso y en la delimitación de 
la frontera occidental. Es decir, consiguió que se reconociera oficialmente a los indígenas como miembros activos de la República brasilera.

Destaquemos por último que el respeto de los positivistas por las tradiciones de las comunidades oprimidas y menos avanzadas, negras o indígenas, no manifiesta ningún relativismo cultural ni afirma la igualdad entre todas las culturas, como lo sostuvo Claude Levi Strauss, quien utilizó las trochas abiertas bajo la dirección de Rondon, durante sus investigaciones antropológicas en Brasil. Para Comte, el progreso es un fenómeno inevitable: el fetichismo inicial será remplazado conforme los fetichistas vayan adoptando el positivismo final. Fiel a su maestro, Rondon miraba a los indios como niños grandes que debían, paulatinamente y según su conveniencia, entrar en la edad adulta (Kury 2003:135-136). Los positivistas brasileros nos ofrecen un ejemplo de paciencia y dedicación que muestra que la posición de Comte frente al colonialismo no constituyó una utopía estéril.

No todos los eurocentrismos promueven el colonialismo. La política positiva de Augusto Comte ilustra la posibilidad de un eurocentrismo moderado y anticolonialista que, aunque afirmaba la superioridad relativa de Europa, condenó y luchó contra la soberbia colonizadora de los occidentales. Si la idea de progreso le hace considerar las naciones europeas como la élite de la Humanidad, también le conduce a resaltar los méritos de los pueblos menos avanzados, sin caer en una sacralización de las diferencias culturales. Sin embargo, su rechazo radical ante la colonización de los Tiempos Modernos no es absoluto, porque no es lo mismo colonizar en una sociedad teológica y militar que en otra científica e industrial. Mientras que sus contemporáneos estimaban que el progreso de los pueblos menos civilizados se conseguía mediante la intervención colonial, la propuesta de Comte consistió en restituir las colonias y en cesar de confundir la occidentalización con la civilización, ya que el desarrollo de un organismo debe provenir de sus adentros y no de una imposición exterior. El positivismo comtiano sostiene una concepción ecuánime de la relaciones entre Occidente y el resto de la humanidad, gracias a la cual sus propuestas suscitaron, por fuera de Francia y Europa, adhesiones sinceras en pro de la defensa de los indígenas oprimidos, por ejemplo en Bengala o en Brasil. 


\section{BIBLIOGRAFÍA}

ARBOUSSE-BASTIDE, P. (1952): Le positivisme politique et religieux au Brésil. De l'Empire à la constitution républicaine. París: Maison d'Auguste Comte.

- (1979): «Sur le positivisme politique et religieux au Brésil », in Le Romantisme, Aspects d'une modernité, $\mathrm{n}^{\circ} 23$, pp.79-97.

ARENDT, H. (1990): On Revolution. Londres: Penguin Books.

ARON R. (1967): «Auguste Comte », in Les étapes de la pensée sociologique. París: Gallimard, pp. 77-140.

- (2006): «Impérialisme et colonialisme » (publicado en 1959), in Les Sociétés modernes. París: PUF, pp. 987-1000.

BAGCHI, J. (2003): «Le positivisme dans l'imagination scientifique du Bengale colonial », in BOURDEAU, M. y CHAZEL Fr. (ed.) (2002): Auguste Comte et l'idée de science de l'homme. París, L'Harmattan, pp. 239-254.

BOURDEAU, M. (2003): "Ciencia, religión y sociedad en Augusto Comte", EMPIRIA, $\mathrm{n}^{\mathrm{o}} 6$, pp 115-125.

- (2008): "La posteridad sociológica de Auguste Comte: Lo normal y lo patológico en Durkheim", EMPIRIA n ${ }^{\circ} 16$, pp.43-58.

BRAGUE, R. (1999): Europe, la voie romaine. París: Gallimard.

BUCHILLET, D. (1997): « De la colonie à la République : Images de l'Indien, politique et législation indigéniste au Brésil », in Cahiers de l'Amérique latine, $\mathrm{n}^{\circ} 23$.

CANGUILHEM, G. (1968): Études d'histoire et de philosophie des sciences, París: Vrin.

CLAEYS Gregory (2010): « Positivist diplomacy », in Imperial Skeptics: British Critics of Empire, 1850-1920. Cambridge: Cambridge University Press, pp. 47-123.

COLLINET, M. (1961): «Le saint-simonisme et l'armée », in Revue française de sociologie, II, 2, pp. 38-47.

CONGREVE R. (1858): L'Inde. París: P. Jannet (traducción francesa del original de 1857).

COMTE, A. (1929): Système de politique positive, ou Traité de sociologie instituant la Religion de l'Humanité. 4 vol., $4^{\text {ta }}$ edición, París : Société Positiviste (Publicado entre 1851 y 1854).

- (1975-1990): Correspondance générale. 8 vol., La Haye: Mouton et París: Vrin.

- (1975): Cours de philosophie positive. 2 vol., París: Hermann, 1975 (Escrito entre 1830 y 1842).

- (1990): Correspondance générale et confessions. 8 vol., Tomo VIII, París : Vrin.

- (1993): Calendrier positiviste ou Système général de commémoration publique. Fontfroide: Fata Morgana (Reproducción facsímile de 1849).

— (1998): Discours sur l'ensemble du positivisme. París: GF (Publicado en 1848).

- (2009): Catéchisme positiviste. París: Sandre (Publicado en 1852).

- (2012): Física social. Madrid: Akal, 2012. Presentación, notas y traducción de las lecciones 46 a 57 del Curso de filosofía positiva por GOBERNA FALQUE J.

COUDERC-MORANDEAU, S. (2007): Philosophie républicaine et colonialisme : origines, contradictions, échecs. Tesis de la Universidad de París X. París: Maison d'Auguste Comte.

GALEANO, E. (2004): Patas arriba, La escuela del mundo al revés. México: Siglo XXI. 
GARCÍA PARPET, M.-Fr. (2003): «Les usages de la pensée française dans le Brésil du XIXe siècle », in BOURDEAU, M. y CHAZEL Fr. (editores) : Auguste Comte et l'idée de science de l'homme. París: L'Harmattan, pp.221-237.

KURY, L. (2003): « Nation, races et fétichisme: la religion de l'humanité au Brésil », in Revue d'Histoire des Sciences Humaines, $\mathrm{n}^{\circ}$ 8, pp.125-137.

LAFFITTE, P. (1882): Toussaint-Louverture, redactado por P. Dubuisson, París: Bureau de la Revue occidentale.

LÉVY-BRUHL L. (2007): Correspondance de John Stuart Mill et d'Auguste Comte. París: L'Harmattan.

MENEZES FERREIRA, L. (2005): « Arqueologia do Sul do Brasil e politica colonial em Hermann von Ihering », in Anos 90, vol. 12, n 21/22, pp. 415-436.

MILL, J. S. (1859): On liberty. Londres: J. W. Parker \& son.

- (1865): Considerations on representative government. Londres: Longman.

NICOLET, C. (1994): L'idée républicaine en France (1789-1924). París: Gallimard.

PETIT, A. (2013): «Le positivisme comtien et la question des races », in TAGUIEFF P.-A., Dictionnaire historique et critique du racisme. París, PUF, pp. 1373-1376.

PICKERING, M. (1993, 2009): Auguste Comte: an Intellectual Biography. 3 vol., New York: Cambridge University Press.

SMITH, A (1863): An inquiry into the nature and causes of the wealth of nations. Edimburgo: Adam \& Charles Black.

TOCQUEVILLE, A. de (2003): Lettres choisies, Souvenirs, 1814-1859. París: Gallimard.

URBAIN, I. (1861): L'Algérie pour les Algériens. París: Michel Lévy frères.

USECHE SANDOVAL T. (2014): L'idée d'occident chez Auguste Comte. Lille: Atelier National de Reproduction des Thèses.

- (2014): «La politique positive et l'Europe: une présentation de l'essai The West de Richard Congreve », in Cahiers philosophiques, $\mathrm{n}^{\circ} 137$, pp. 86-101.

WRIGHT, T. R. (1986): The Religion of Humanity: The Impact of Comtean Positivism on Victorian Britain. Cambridge: Cambridge University Press. 